\title{
Application of a Moving-Coordinate Prediction Model to East Coast Cyclones ${ }^{1}$
}

\author{
Keith W. Veigas and Frederick P. Ostby, JR. \\ The Travelers Research Center, Ine., IIartford, Conn.
}

(Manuscript received 17 August 1962)

\begin{abstract}
A statistically derived procedure for forecasting the 24-hr displacement, change in central pressure, and change in intensity of east coast cyclones is presented. The analysis is based on a moring coordinate systemi.e., predictor information is measured at points fixed with respect to the moving cyclone center rather than at points fixed with respect to the earth.

Two sets of multiple linear regression prediction equations are derived from a sample of 352 cyclone cases. The first set is based solely on point values of sea-level pressure, 500 -mb height, $1000-500$-mb thickness, and 12 -hr changes of these variables. The second set is based on point values plus a series of quantities derived from point values such as steering components, gradients, vorticity and thickness advection, and thermal wind.

When applied to 106 independent cases, the point value equations yield a vector position root-meansquare (rms) error of $4.01 \mathrm{deg}$ of latitude and a central pressure rms error of $8.70 \mathrm{mb}$. The complex equations fail to improve these scores significantly.

Operational $24 \mathrm{hr}$ forecasts made for 31 cases during the winter of 1959-1960 are compared with corresponding 18-hr forecasts prepared by the National Weather Analysis Center (NWAC). The statistical forecasts incur a vector rms error of $2.25 \mathrm{deg}$ of latitude for position and a rms error of $8.14 \mathrm{mb}$ for deepening; NWAC forecasts incur a rms error of $3.87 \mathrm{deg}$ of latitude and a rms error of $7.25 \mathrm{mb}$ for deepening.
\end{abstract}

\section{Introduction}

This study is concerned with the derivation of objective techniques for predicting the behavior of winter cyclones located near the east coast of the United States. Many of these cyclones undergo intense and rapid development, leading to widespread cloudiness, low ceilings, abundant precipitation, and high winds along much of the eastern seaboard. Most of the heavy snowstorms along the east coast are a consequence of this type of development. These facts, coupled with the generally high frequency of occurrence of such cyclones, emphasize the importance of this forecast problem.

A further objective of the experiment is to examine the usefulness of formulating the prediction problem in terms of the behavior of significant features of the sealevel pressure field rather than in terms of individual pressure values over a grid of points. Since significant features can often be associated with weather parameters of interest, such a formulation should be particularly meaningful and of practical assistance to the synoptic meteorologist.

The cyclone's position and its future intensity are of primary concern in the preparation of a forecast of the

\footnotetext{
1 This work was supported by Geophysics Research Directorate, Air Force Research Division, under Contract AF 19(604)-5207 and by the Federal Aviation Agency under Contract FAA/BRD363.
}

weather associated with an impending east coast cyclone.

This of course does not imply that associated weather conditions can be completely deduced from the future position and intensity of a cyclone. Nevertheless, it is generally recognized that position and intensity prognoses are basic and indispensable factors in the weather forecast. In this study, prediction equations for the 24-hr displacement and change in intensity of wintertime east coast cyclones are derived and tested.

\section{Review of the problem}

Cyclones over the eastern lnited States have long been of interest, but were not subject to very intensive investigation until after World War II. Bowie and Weightman (1914) computed the average 24-hr movement of cyclones over the United States, by months, as a function of current location and area of origin. Although these analyses can depict the climalological features of cyclone displacement, studies by Miller (1946), Quiring2, and Hering and Mount (1956) all indicate that the statistics of average movements have little predictive value. Miller (1946), for example, compiled data which described the characteristics of newly formed cyclones in the Atlantic coastal region.

\footnotetext{
${ }^{2}$ Quiring, R. F., 1953: An evaluation of the Bowie-Weightman
} storm tracks. (M.S. thesis), New York University, $23 \mathrm{pp}$. 
This study showed the extreme variability in 24 -hr displacements of 208 cyclones and demonstrated that a forecast based solely on the most frequent 24 -hr movement would have only about one chance in four of verifying within a distance of $3 \mathrm{deg}$ of latitude (180 n $\mathrm{mi})$.

In recent years, many attempts have been made to develop techniques to improve east coast cyclone forecasting. These studies included theoretical, empirical, and synoptic procedures; all have met with varying degrees of success. On the theoretical side, there have been numerous contributions to the theory of cyclone development (Sutcliffe, 1947; Sutcliffe and Forsdyke, 1950; and Petterssen, 1956), but little has been done to apply these results directly to daily forecasting problems, except perhaps in a qualitative fashion. The direct approach of dynamical forecasting of cyclone behavior, either by numerical methods (Charney, 1954) or by graphical methods (Estoque, 1957) has shown only a small amount of success.

On the empirical side, a variety of graphical correlation techniques have been attempted, including studies by Palmer (1948), George ${ }^{3}$, and Shafer and Funke. ${ }^{4}$ Palmer's technique, for example, employed graphical correlation diagrams to depict the relationships between various features of the weather map and the movement of cyclones; this study yielded results which compared favorably with subjective forecasts made by the WBAN Analysis Center (now the National Weather Analysis Center). Other objective techniques of interest were developed by Austin (1947), Longley (1947), Rampey (1953), and Hering and Mount (1956).

The skill of the synoptic forecaster has remained unchallenged despite the availability of many objective procedures for predicting cyclone movement and intensification (see, for example, Petterssen, Estoque and Hughes, 1957). The technique of synoptic meteorologists can be called empirical-synoptic. Published studies, the forecaster's experience, "sets of rules" passed along from more experienced forecasters, and ideas based on theoretical results, provide the basic foundation for the derivation of these techniques. The synoptic meteorologist's decision concerning the relative weight to be assigned to each of several different pieces of information, nevertheless, stil] remains largely subjective.

It would appear desirable, therefore, for any derivation of objective forecast methods to be based as much as possible on all the available theoretical, empirical, and synoptic "know how." The aim would be to include as quantitative predictors in the forecast procedure all of the meteorological parameters considered to be im-

\footnotetext{
${ }^{3}$ George, J. J., et al. 1953: Forecasting relationships between upper-level flow and surface meteorological processes. Geophysics Research Paper No. 23, AFCRC Technical Report 53-28, 186 pp.

${ }^{4}$ Shafer, R. J., and P. W. Funke, 1954: Further studies on the relation between upper-level and surface meteorological processes. Scientific Report No. 2, Eastern Airlines, 35-47.
}

portant in cyclone behavior. The derivation of such methods always involves two steps: first, a specification of an initial large set of possible predictors; and, second, a subsequent limitation of the number of predictors to only those furnishing independent and significant predictive information. It is in the first step that the meteorologist must call upon his professional knowledge. In the second step certain statistical methods can be used to select the predictors in a meaningful and systematic fashion.

In this study, for example, theoretical-empiricalsynoptic information was called upon not only in the specification of the particular predictors to be used but also - and perhaps more importantly - in the procedure adopted for measuring these predictors. The rationale for the procedure used is as follows:

It can be assumed that the movement and change in intensity of a cyclone is a function of parameters either measured at fixed geographic locations (i.e., independent of the cyclone's location) or measured relative to the cyclone's location. Synoptic experience favors the latter assumption in the following way. Consider, the case of a cyclone approaching a station from the northwest. In general, the forecaster can readily locate the position of the cyclone's center and identify its characteristics. Then, directing his major attention to that feature of the map (i.e., the cyclone), the forecaster predicts its movement and change in characteristics. If the cyclone were approaching from the southwest, or for that matter from any other direction, he would direct his major attention in that direction. Clearly, his procedure is first to identify the feature and then examine its characteristics in whatever location relative to the object station it might be. This well-established and generally recognized synoptic procedure can quite simply and directly be incorporated into a statistical analysis if parameters are measured not at fixed geographical locations but rather are measured relative to the center of the identified cyclone, regardless of its absolute position. Such a procedure was adopted in this study.

The second step in the derivation-the limitaton of the number of predictors-follows from the necessity, on statistical grounds, that the number of predictors be small relative to the number of observations of each predictor. If the number of predictors is too large, a relationship which fits the sample used to establish it is likely to fail when applied to a new sample. Loren $z^{5}$ refers to this problem as " the bugaboo of statistical forecasting." To overcome this problem, it is necessary either to increase the size of the sample or to limit the number of predictors. The latter alternative is generally more feasible and has been discussed at length by Wadsworth and Bryan (1948), Miller and Malone (1954), and

\footnotetext{
${ }^{5}$ Lorenz, E. N., 1959: Prospects for statistical weather forecasting. Final Report, Contract No. AF19(604)-1566. Department of Meteorology, M.I.T.,Cambridge, Mass., 185 pp.
} 
Lorenz. ${ }^{6}$ The screening procedure of Miller (1962) is one appropriate method for achieving this predictor limitation and is the one adopted in this study.

\section{Data sources}

The data for this study were acquired from two sources. Manuscript surface and $500-\mathrm{mb}$ maps; prepared by the United States Weather Bureau at Idlewild Airport, were used for compiling the dependent data sample covering the 8-yr period, 1949-1956. These maps used a Lambert Conformal Conic Projection, scale $1: 12,500,000$, with standard parallels at 30 and $60 \mathrm{~N}$. In addition, microfilm maps (surface and upper air) for 1957-1958, analyzed by the National Weather Analysis Center, were used for independent data testing. These maps used a Polar Stereographic Projection, scale $1: 20,000,000$, with standard parallel at $60 \mathrm{~N}$.

\section{Selection of the sample of data}

Cases for the dependent sample were selected from cyclone tracks located in the geographical area shown in Fig. 1, during the months November through March, for the years 1949 through 1956. In order to include upper-air data in the derivation of prediction equations, it was necessary to consider cyclones at $0030 \mathrm{GCT}$ and 1230 GCT only, which are the times that conform most closely with the $0300 \mathrm{GCT}$ and $1500 \mathrm{GCT}$ upper-air observations. (These times have since been changedsurface and upper-air observations are now coincident at $0000 \mathrm{GCT}$ and $1200 \mathrm{GCT}$.)

A sea-level cyclone (characterized by at least one closed isobar initially as well as $24 \mathrm{hr}$ later) was selected for the sample when it first appeared in the area of Fig. 1, If $12 \mathrm{hr}$ later, the cyclone was still situated within the defined area, it was included as another case. In order to eliminate a possible bias, any cyclone remaining in the area after two 12 -hr periods was not included a third time.

Based upon the above requirements, 352 cases were selected. These cases are tabulated in Table 1. (Weather data for November 1950 were not available at the time.) The number of cases studied ranged from as many as 15 in November 1949 to as few as 2 in November 1953. The maximum number of cases occurred during the month of February (an average of 11.6) and the minimum in November (an average of 7.1 ).

\section{Characteristics of the data}

Some characteristics of the behavior of east coast cyclones can be derived from the sample of 352 cases. If the 24 -hr displacement vectors for the dependent sample are plotted with co-incident origins, isopleths of

${ }^{6}$ Same as footnote 5 . the percentage frequency of the cyclone's terminal location can be obtained (see Fig. 2). This is the same procedure used by Miller (1946). Fig. 2 shows that the modal displacement is toward the east-northeast at 10 to $15 \mathrm{deg}$ of latitude per $24 \mathrm{hr}$. This sample of cyclones exhibits a large variability in both direction and speed; J. Miller's sample of east coast cyclones for the period 1929-1939 also showed a large variability in direction and speed with a $24-\mathrm{hr}$ modal displacement of $9.5 \mathrm{deg}$ of latitude at a heading $55 \mathrm{deg}$ east of north.

Fig. 3 shows the frequency distribution of $24-\mathrm{hr}$ change in central pressure of the 352 cyclone cases.

TABle 1. Cyclone frequency data.

\begin{tabular}{lcrrrrr}
\hline \hline & Nov. & Dec. & Jan. & Feb. & Mar. & Total \\
\hline $1948-49$ & - & - & 4 & 13 & 7 & 24 \\
$1949-50$ & 15 & 4 & 3 & 11 & 12 & 45 \\
$1950-51$ & - & 13 & 8 & 10 & 6 & 37 \\
$1951-52$ & 4 & 7 & 8 & 13 & 15 & 47 \\
$1952-53$ & 6 & 5 & 9 & 8 & 11 & 39 \\
$1953-54$ & 2 & 8 & 11 & 12 & 10 & 43 \\
$1954-55$ & 7 & 7 & 13 & 13 & 10 & 50 \\
$1955-56$ & 9 & 4 & 12 & 13 & 11 & 49 \\
$1956-57$ & 7 & 11 & - & - & - & 18 \\
Total & 50 & -59 & -68 & -93 & 82 & 352 \\
Av. per mon & 7.1 & 7.4 & 8.5 & 11.6 & 10.2 & \\
\hline
\end{tabular}

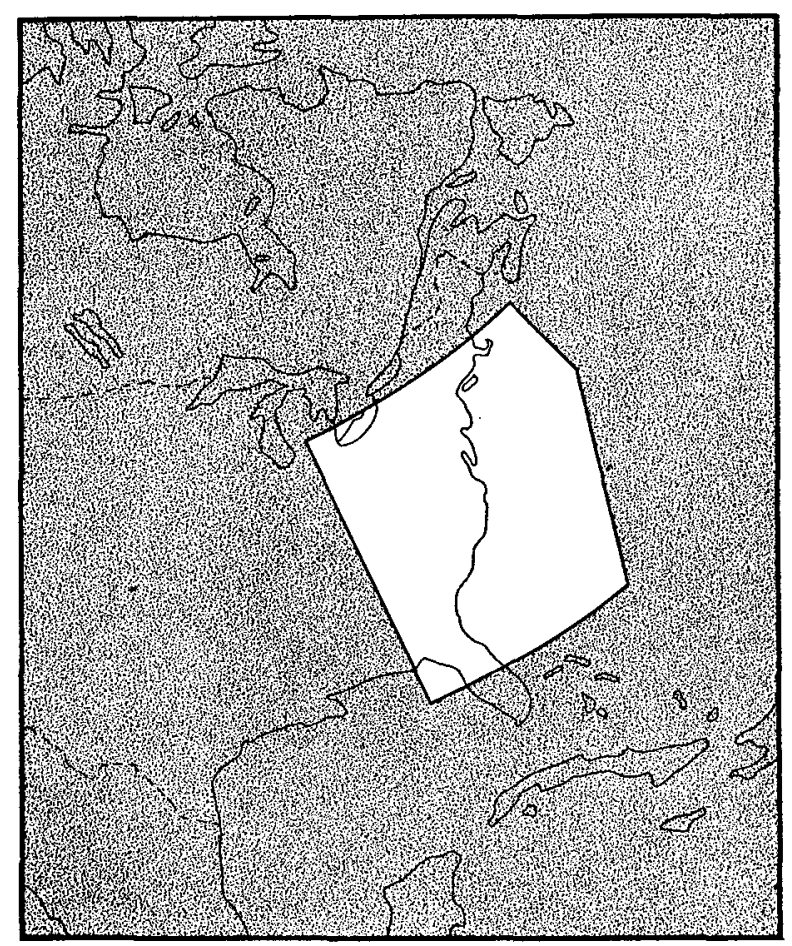

Fig. 1. Cyclone prediction area. 


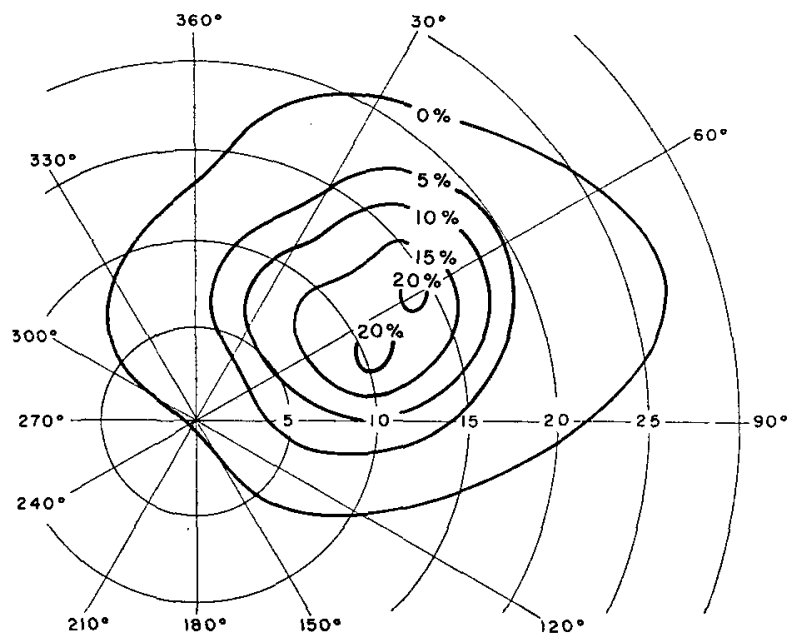

FIG. 2. Twenty-four hour movement of 352 cyclones. Concentric circles are in intervals of $5 \mathrm{deg}$ of latitude. Origin represents initial cyclone locations. Isopleths represent equal probabilities of a cyclone being located within 3 degrees of latitude of any point after 24 hours.

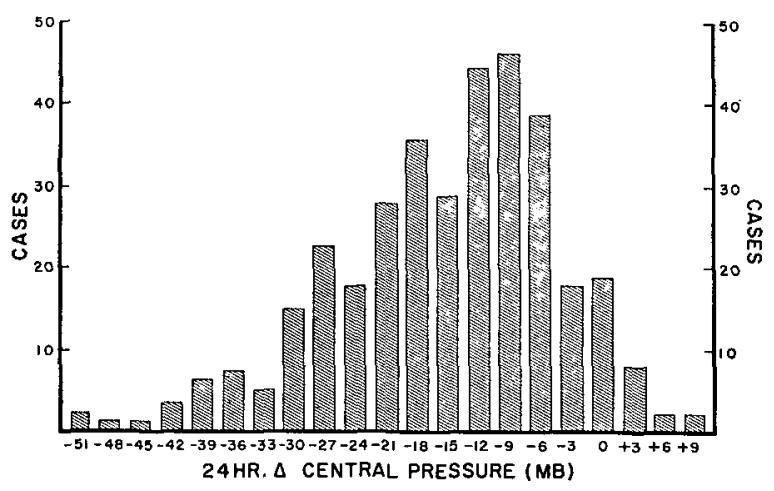

FIG. 3. Frequency distribution of 24 -hr change in central pressure of 352 cyclones.

While a few cyclones displayed filling tendencies, the great majority deepened, and in a few cases this deepening was greater than $50 \mathrm{mb}$.

\section{Selection of possible predictors}

Although statistical procedures permit examination of, and selection from, a large number of possible predictors, the analysis itself is not based on knowledge of the physical processes that govern the behavior of the atmosphere. It therefore appears highly desirable to incorporate dynamic principles and synoptic experience in the selection of the initial large set of predictors. A considerable effort was made to specify a set of possible predictors containing as much predictive information as could be derived from the data available.

A. Grid: The type of grid used in this study was a moving grid centered over the cyclone center. Meteorological information was tabulated at locations fixed with respect to the cyclone center rather than with respect

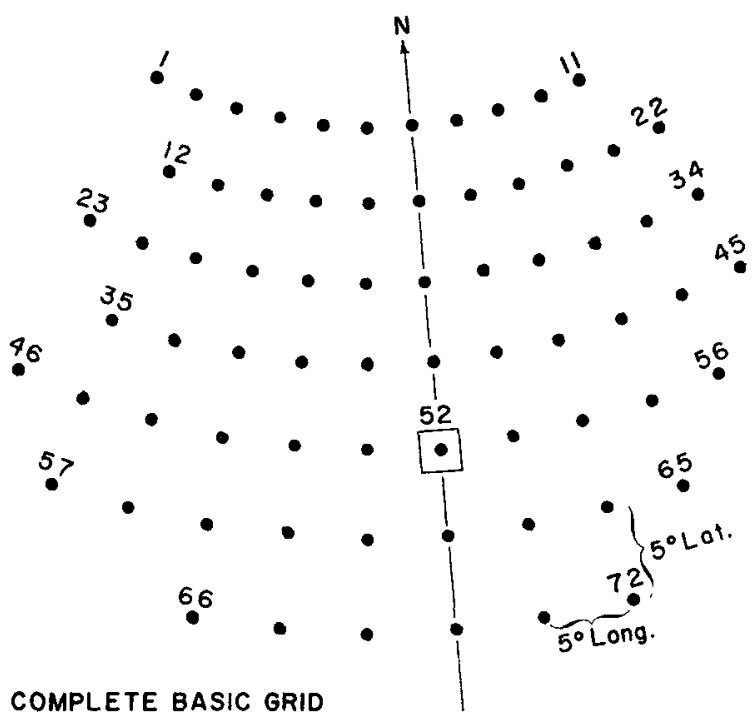

Fig. 4. Complete basic grid. The grid is constructed on a map with gridpoint 52 located at $35 \mathrm{~N}, 75 \mathrm{~W}$. Remaining gridpoints are located at 5 deg latitude and longitude intersections.

to specific geographical locations. The basic grid is shown in Fig. 4. This grid can be constructed by defining the location of grid point 52 at $35 \mathrm{~N}, 75 \mathrm{~W}$. The remaining grid points then are located at the $5 \mathrm{deg}$ latitude and longitude intersections. Special grids for tabulating specific information are sub-sets of the basic grid and maintain the same numbering system for various grid points.

$B$. Types of predictors: The types of possible predictors considered can be divided into two general classes: "point value" and "complex" predictors. In general, the point value predictors include directly observable atmospheric variables at individual grid points, while the complex predictors include variables derived by applying finite difference methods to observations at sets of grid points.

C. Point value predictors: The following variables (see Table 2) were tabulated as possible predictors at points on the basic grid: sea-level pressure, 12-hr pressure change, $500-\mathrm{mb}$ height, 12 -hr $500-\mathrm{mb}$ height change, $1000-500$-mb thickness, 12-hr thickness change, cyclone location (latitude and longitude), cyclone intensity, and maximum $500-\mathrm{mb}$ temperature gradient.

The intensity of the cyclone at $t_{0}$ provides a measure of cyclonic circulation and was derived by averaging the sea-level pressure at four grid points surrounding the cyclone, and then subtracting the central sea-level pressure.

The maximum $500-\mathrm{mb}$ temperature gradient is a measure of the mid-tropospheric baroclinicity and was defined as the difference between the $500-\mathrm{mb}$ temperature over the cyclone center and the coldest temperature in the northwest quadrant within $1000 \mathrm{mi}$ of the cyclone. This parameter was previously applied by George. ${ }^{7}$

\footnotetext{
${ }^{7}$ Same as footnote 3.
} 
TABLE 2. Possible predictors to be screened for various types of prediction equations: $A$ (surface, $500-\mathrm{mb}$, and $1000-500-\mathrm{mb}$ thickness), $B$ (all predictors available, including complex terms).

\begin{tabular}{|c|c|c|c|c|}
\hline Predictor type & Symbol & $\begin{array}{l}\text { Number } \\
\text { of pre- } \\
\text { dictors }\end{array}$ & $\mathrm{Eq} \mathrm{A}$ & Eq B \\
\hline Sea-level pressure & $P$ & 49 & $x$ & $\mathrm{x}$ \\
\hline Sea-surface temperature & $T_{8}$ & 1 & $\mathrm{x}$ & $\mathrm{x}$ \\
\hline Cyclone intensity & $I_{0}^{\circ}$ & 1 & $\mathrm{x}$ & $\mathrm{x}$ \\
\hline 12-hr pressure change & $\Delta P$ & 15 & $\mathrm{x}$ & $\mathrm{x}$ \\
\hline Cyclone location & $A, O$ & 2 & $\mathrm{x}$ & $\mathrm{x}$ \\
\hline Sea-level pressure gradients & $\frac{\partial P}{\partial x}, \frac{\partial P}{\partial y}$ & 68 & & $\mathrm{x}$ \\
\hline 500-mb height & $Z^{y}$ & 43 & $\mathrm{x}$ & $\mathrm{x}$ \\
\hline 12-hr 500-mb height change & $\Delta Z$ & 43 & $\mathrm{x}$ & $x$ \\
\hline $\begin{array}{l}\text { Maximum } 500-\mathrm{mb} \text { temp. } \\
\text { gradient }\end{array}$ & $\nabla T$ & 1 & $\mathrm{x}$ & $\mathrm{x}$ \\
\hline 500 -mb height gradients & $\frac{\partial z}{\partial x}, \frac{\partial z}{\partial y}$ & 52 & & $\mathrm{x}$ \\
\hline 500-mb steering components & $\bar{u}, \bar{v}$ & 2 & & $\mathrm{x}$ \\
\hline $500-\mathrm{mb}$ steering tendencies & $\Delta \bar{u}, \Delta \bar{v}$ & 2 & & $\mathrm{x}$ \\
\hline 500-mb absolute vorticity & $\eta$ & 22 & & $\mathrm{x}$ \\
\hline $500-\mathrm{mb}$ vorticity advection & $A \eta$ & 11 & & $\mathrm{x}$ \\
\hline 12 -hr 500 -mb vorticity change & $\Delta \eta$ & 22 & & $\mathrm{x}$ \\
\hline $1000-500$-mb thickness & $H$ & 30 & $\mathrm{x}$ & $\mathrm{x}$ \\
\hline 12-hr thickness change & $\Delta H$ & 9 & $\mathrm{x}$ & $\mathrm{x}$ \\
\hline Thermal wind components & $\bar{u}_{t}, \bar{v}_{t}$ & 2 & & $\mathrm{x}$ \\
\hline Thermal wind tendency & $\Delta \bar{u}_{t}, \Delta \bar{v}_{t}$ & 2 & & $\mathrm{x}$ \\
\hline Thickness configuration & $D, G$ & 2 & & $\mathrm{x}$ \\
\hline Thickness advection & $A_{h}$ & 14 & & $\mathrm{x}$ \\
\hline $\begin{array}{l}\text { Laplacian of thickness } \\
\text { advection }\end{array}$ & $\nabla^{2} A_{h}$ & 3 & & $\mathrm{x}$ \\
\hline Thermal vorticity & $\zeta_{t}$ & 12 & & $\mathrm{x}$ \\
\hline Thermal vorticity advection & $A_{t}$ & 3 & & $\mathrm{x}$ \\
\hline \multirow[t]{2}{*}{ 12-hr thermal vorticity change } & $\Delta \zeta_{t}$ & 1 & & $\mathrm{x}$ \\
\hline & & 412 & 194 & 412 \\
\hline
\end{tabular}

D. Complex predictors: The following "complex" variables (see Table 2) were computed and tabulated at selected grid points for use as possible predictors: sea-level pressure gradient, 500-mb height gradient, $500-\mathrm{mb}$ steering components, $500-\mathrm{mb}$ steering tendency, thermal wind components, $500-\mathrm{mb}$ absolute vorticity, $12-\mathrm{hr} 500-\mathrm{mb}$ vorticity change, $500-\mathrm{mb}$ vorticity advection, thickness configuration, thickness advection, Laplacian of thickness advection, thermal vorticity, thermal vorticity advection, and 12-hr thermal vorticity change.

Various steering techniques for forecasting the displacement of cyclones, such as those developed by Austin (1947), Longley (1947), Palmer (1948), and Rampey (1953), are widely used by practicing forecasters. East-west and north-south components of the geostrophic wind over the cyclone were derived from the $500-\mathrm{mb}$ height values surrounding the cyclone position and are measures of steering that were used as possible predictors. These components were also computed on the $500-\mathrm{mb}$ chart at $t_{-12}$ in order to include steering tendency (see, for example, Shafer and Funke ${ }^{8}$ ) as a possible predictor.

\footnotetext{
${ }^{8}$ Same as footnote 4.
}

The absolute geostrophic vorticity at $500 \mathrm{mb}$ was computed (by finite difference methods) at $t_{0}$ and $t_{-12}$ in order to obtain fields of absolute geostrophic vorticity and their 12-hr change. In addition, the advection of $500-\mathrm{mb}$ geostrophic vorticity with the $500-\mathrm{mb}$ geostrophic wind was determined by finite difference methods over the grid.

Various thickness gradients were computed over and upstream from the cyclone position. The configurations of thickness patterns and their relation to cyclone development have been investigated by Sutcliffe and Forsdyke (1950).

The advection of the $1000-500-\mathrm{mb}$ thickness field with the $500-\mathrm{mb}$ geostrophic wind was determined over the grid. In addition, computations were made of the Laplacian of the thickness advection which was suggested to be of importance in cyclone development by Petterssen (1956).

Computations of vorticity from the $1000-500-\mathrm{mb}$ thickness field yielded the "thermal vorticity" field. Also, the advection of thermal vorticity by the thermal wind, known as the "development" or "baroclinic" term (Sutcliffe, 1947), was computed.

In all, 194 point value and 218 complex predictors (see Table 2) plus four predictands (north-south and east-west components of 24-hr displacement, 24-hr change in central pressure, and 24-hr change in intensity) were computed. In the subsequent statistical analysis two sets of prediction equations were derived: $A$, which was based on using only the 194 point value predictors; and $B$, which was based on the 194 point value predictors plus the 218 complex predictors.

\section{Mathematical methods}

The reduction of the number of predictors was accomplished using the screening procedure suggested by Bryan $^{9}$ and developed and programmed for the IBM-704 by Miller. ${ }^{10}$ The object of the screening procedure is to select from a set of possible predictors a sub-set which contributes significantly and independently to reducing the variance of the predictand. From an array of possible predictors, that predictor which has the highest linear correlation with the predictand in question is selected. Partial correlation coefficients between the predictand and each of the remaining predictors, holding the first selected predictor constant, are then examined. The predictor associated with the highest coefficient is the second one selected. Additional predictors are then chosen in a similar fashion. This

${ }^{9}$ Bryan, J. G., 1944: Special techniques in multiple regression, Unpublished manuscript.

${ }_{10}$ Miller, R. G., 1958c: A computer program for the screening procedure. Studies in statistical weather prediction, Final Report, Contract No. AF19(604)-1590, Travelers Weather Research Center, 96-136. 
procedure is repeated until a selected predictor fails to explain a significant additional percentage of the remaining variance of the predictand.

The criterion of significance as applied to the screening procedure is not clear-cut since the usual $F$ test methods (see, for example, Snedecor, 1946) are not applicable (Niller, 1962). When a predictor is chosen at random from a group of predictors, an $F$ test is usually performed. The critical $F$ is usually taken at the 95 per cent level; this allows for a one in twenty chance for considering a predictor significant when in fact it is not. In the screening procedure the selection of a predictor is not a random choice. Therefore, it is necessary to devise a more severe test to specify a one in twenty chance occurrence. For the screening procedure Miller (1962) suggested that the critical $F$ value be a function of the number of possible predictors. The $F$ test was used in this form in these experiments.

Predictors were selected for each of the four predictands and the associated multiple linear regression equations derived. Forecasts were then made for 106 cases not used in the development of the equations.

\section{The prediction equations}

The prediction equations derived from the regression analysis have the form

$$
\hat{Y}=A_{0}+A_{1} X_{1}+A_{2} X_{2}+\cdots+A_{n} X_{n},
$$

where $\hat{Y}$ is the predictand, the coefficients $A_{0}, A_{1}, \cdots A_{n}$ are constants derived from the developmental sample, and the $X$ 's are the predictors selected by the screening procedure.

In the following two sets of prediction equations,

$\hat{N}=$ predicted 24 -hr northward displacement, in degrees of latitude

$\widehat{E}=$ predicted $24-\mathrm{hr}$ eastward displacement, in degrees of latitude

$\hat{D}=$ predicted 24 -hr change in central pressure, in millibars

$\hat{I}=$ predicted 24 -hr change in intensity, in millibars.

$$
\text { Type } A \text { (point values) }
$$

$$
\begin{aligned}
\hat{N}=17.4854+0.0333(Z)_{56}-0.0260(Z)_{37} \\
-0.0455(\Delta P)_{30}-0.3337(A)-0.0302(P)_{17} \\
+0.1225(P)_{43}-0.0407(\Delta Z)_{39}-0.0201(Z)_{59} \\
-0.0835(P)_{30}
\end{aligned}
$$

$$
\begin{aligned}
& \hat{E}=- 210.5670+0.0288(Z)_{20}-0.0644(Z)_{61} \\
&+0.2085(P)_{30}+0.0324(H)_{29}-0.0329(\Delta Z)_{50} \\
& \hat{D}=84.1734+0.0972(\Delta Z)_{39}-0.1623(Z)_{66} \\
&+0.0659(Z)_{16}-0.1709(\Delta Z)_{48}+0.8679\left(I_{0}\right) \\
&+0.4254(\Delta P)_{52}
\end{aligned}
$$

$$
\begin{array}{r}
\hat{I}=-35.2177-0.9311\left(I_{0}\right)+0.1332(\Delta Z)_{48} \\
-0.3622(\Delta P)_{52}+0.0866(Z)_{66}-0.0401(Z)_{29} \\
+0.0572(\Delta Z)_{45}
\end{array}
$$

Type B (complex)

$$
\begin{aligned}
\hat{N}= & -115.6356+1.2144(\bar{v})_{52}+0.2011\left(\frac{\partial Z}{\partial y}\right)_{39} \\
& +0.0453\left(A_{h}\right)_{42}-2.1527(\Delta \eta)_{61}+0.1568(Z)_{1} \\
\hat{E}= & -108.3379-0.4134\left(\frac{\partial Z}{\partial y}\right)_{41}+0.1696\left(\frac{\partial Z}{\partial x}\right)_{39} \\
& +1.1885(P)_{42}-0.1641\left(\frac{\partial Z}{\partial x}\right)_{48}-0.2275\left(\frac{\partial Z}{\partial y}\right)_{52} \\
\hat{D}= & 52.3902-0.2674(\bar{u})_{52}-0.1652(\Delta Z)_{48} \\
& +0.5358\left(\frac{\partial P}{\partial y}\right)_{52}+0.4859(\Delta P)_{41}-0.1178(Z)_{66} \\
& +0.0365(Z)_{16}+0.1396\left(\frac{\partial p}{\partial x}\right)_{14}+0.0323(0)
\end{aligned}
$$

The predictors, listed in the order of their selection, are represented in most cases by a number and a symbol. The number refers to the location of the predictor in the Fig. 4 grid; the symbols are defined in Table 2. Units for $P, \Delta P$, and $I_{0}$ are $\mathrm{mb}$; for $Z$ and $H$ units are decafeet with the ten-thousand digit omitted; for $\Delta Z$, units are decafeet. Note that a Type $B$ equation for change in intensity was not derived.

The percentage of the total variance of a predictand explained by each selected predictor is given in Table 3. In general, the first two or three predictors explain a considerable amount of the variability; subsequent predictors explain smaller amounts.

It is of considerable interest to examine these equations from the point of view of a synoptician's experience. One way to do this is to attempt to interpret the significance and implications of the various predictors and their associated coefficients in synoptic terms. Such analyses must be viewed with caution, because interactions may occur among its individual predictor elements, requiring any multiple regression equation to be considered in its entirety. Nevertheless, it is possible to look at some of the leading predictors in these equations and discuss them in meaningful synoptic terms.

\section{A. Type A (point values)}

1. Northward displacement ( $E q 2)$ : (Positive values of this predictand refer to northward displacement, and negative values refer to southward displacement). The 
TABLE 3. Selected predictors and per cent reduction of variance contributed by each predictor-dependent data. Predictors, in the order of their selection, are represented by their gridpoint number and symbol, along with the per cent reduction of variance $(P R)$ contributed by each, for both Type $A$ and $B$ equations.

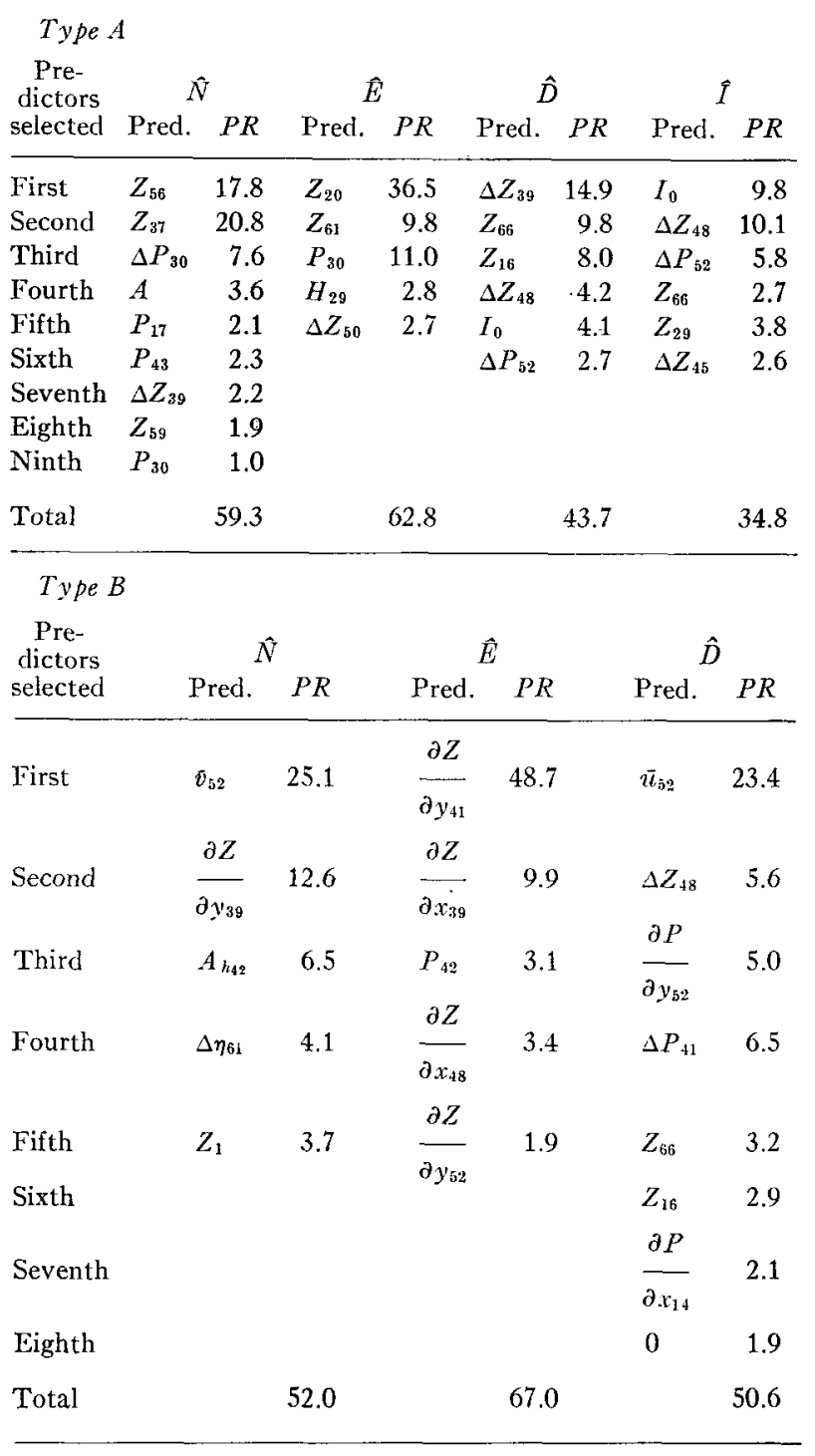

first predictor selected is the 500 -mb height at grid point 56, located about 20 deg of longitude east of the cyclone center. The sign of the coefficient suggests that the greater the $500-\mathrm{mb}$ height value in this region, the greater the tendency for the cyclone to move northward during the subsequent $24 \mathrm{hr}$. A well-developed $500-\mathrm{mb}$ ridge to the east of the surface cyclone, of course, is a pattern familiar in situations of large northward displacement of the cyclone.

The second predictor selected is the $500-\mathrm{mb}$ height at grid point 37. This predictor, located west-northwest of the cyclone, is weighted to favor northward motion of the cyclone when the height at that grid point is low.
An example of this type of situation would be a large amplitude trough to the west of the sea-level cyclone.

It is interesting to note that these first two predictors have coefficients which are of similar magnitude and opposite sign. This combination of predictors may be interpreted as analogous to a 500 -mb height gradient across the cyclone center. These first two predictors (see Table 3) account for about 38 per cent of the total variability (in the dependent data) of northward cyclone displacement.

2. Eastward displacement ( $E q$ 3): (Negative values of this predictand refer to eastward displacement, and positive values refer to westward displacement.) The first predictor selected is the $500-\mathrm{mb}$ height at grid point 20 , located approximately $2000 \mathrm{mi}$ to the northeast of the cyclone. The coefficient of this predictor implies that high heights to the northeast are associated with large positive displacements (westward) or small negative displacements (eastward) and that low heights are associated with large eastward displacements. This agrees with synoptic experience: a deep 500-mb cyclone over northern latitudes implies a fairly strong zonal wind pattern at middle latitudes, which in turn is conducive to large eastward cyclone displacements. On the other hand, above normal heights at northern latitudes suggest blocking action or systems with large amplitudes, which tend to retard the eastward movement of sea-level cyclones. This predictor accounts for approximately 36 per cent of the total variability of eastward cyclone displacements.

3. Deepening ( $E q$ 4): (Negative values of this predictand represent cyclone deepening, and positive values represent filling.) The first predictor selected is the $12-\mathrm{hr}$ $500-\mathrm{mb}$ height change at grid point 39 , located to the northwest of the cyclone center. Its coefficient implies that height falls in this region are associated with deepening, while height rises are associated with filling, a relationship which is in general accord with synoptic reasoning. The reduction of variance explained by this predictor is 15 per cent.

4. Intensification ( $E q$ 5): In this study the cyclone intensity is defined as the difference between the central pressure of the cyclone and the average of four sea-level pressures about the cyclone center (grid points 39, 41, 61 and 63). Positive values of this predictand represent increasing intensity. The first predictor selected is the initial intensity itself. Its coefficient may be interpreted as follows: cyclones which are initially intense do not tend to intensify further, while weak cyclones are likely to undergo intensification. The second predictor selected is the 12 -hr 500 -mb height change at grid point 48 , located to the west of the cyclone center in a region which is usually in the northwesterly flow to the rear of

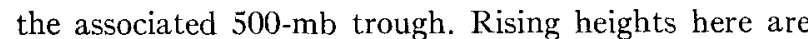
associated with intensification. The reduction of variance explained by these two predictors is 20 per cent. 


\section{B. Type B (complex)}

1. Northward displacement $(E q 6)$ : The first predictor selected is the meridional component of the $500-\mathrm{mb}$ geostrophic wind over the sea-level cyclone center. Its interpretation is straightforward: a strong southerly flow aloft over the cyclone center contributes to large northward cyclone displacement. The reduction of variance explained by this predictor is 25 per cent.

2. Eastward displacement ( $E q 7)$ : The first predictor selected is the north-south $500-\mathrm{mb}$ height gradient which is proportional to the $500-\mathrm{mb}$ zonal wind component) to the northeast of the cyclone. It reflects the fact that strong westerlies aloft to the northeast of the cyclone are related to large eastward cyclonic displacement. It is interesting to note that there is apparently more predictive information in the zonal wind to the northeast of the cyclone than directly over it. This interpretation is consistent with the practice of synoptic meteorologists, who usually direct their attention to the upper-air flow pattern in the direction in which the cyclone may be moving rather than to a position directly over it. The reduction of variance explained by this predictor is 49 per cent.

3. Deepening ( $E q$ 8): The first predictor selected is the zonal component of the 500 -mb geostrophic wind over the cyclone center. Bailey ${ }^{11}$ also found the strength of the wind field over cyclones to be an important factor in cyclone deepening. Further, synoptic meteorologists tend to associate large horizontal temperature differ-

${ }^{11}$ Bailey, R. E., 1958: Further studies in the development of short-range weather prediction techniques. Scientific Report No. 1, Contract No. AF 19(604)-2073. Eastern Airlines, 142-157. ences with cyclone deepening, and one implication of a strong zonal wind is the presence of a large north-south thermal gradient. The reduction of variance explained by this predictor is 23 per cent.

It is particularly noteworthy that in most of the above prediction equations the leading predictors are 500 -mb rather than sea-level variables.

\section{Results}

The sets of equations described in the previous section were derived from 352 dependent cases. Some of the characteristics of these equations are given in Table 4.

Note that the Type B equations yield slightly better results for eastward displacement and deepening, whereas Type A equations produce a larger per cent reduction than Type B for the northward displacement. When applied to independent data, however, the difference in results between these two types of equations is even smaller (see Table 5).

The prediction equations were applied to 106 independent cases. The results of all the independent prediction are summarized in Table 5. For comparative purposes, some of the statistics of the dependent data are also presented in Table 5 .

Table 5 demonstrates that the Type A and B equations exhibit stability when applied to the 106 independent cases: the root-mean-square vector position errors were 3.50 and $4.01 \mathrm{deg}$ of latitude, respectively.

The results of the 106 independent Type A predictions are shown graphically in Fig. 5. In Fig. 5 the origin represents the actual location of the cyclone at verification time. Each circle represents the predicted location,

Table 4. Prediction statistics-dependent sample. Characteristics of prediction equations are presented, including the number of predictors in each equation, the number of possible predictors from which the selection was made, the total and residual variances, the per cent reduction of variance, and the root-mean-square error, for equations of Type A (point values) and B (complex) for the four predictands, $\hat{N}$ (24-hr northward displacement), $\hat{E}$ (24-hr eastward displacement), $\hat{D}$ (24-hr change in central pressure), and $\hat{I}$ (24-hr change in intensity). The statistical measures are defined in Appendix B.

\begin{tabular}{|c|c|c|c|c|}
\hline \multicolumn{5}{|l|}{ Type A: } \\
\hline Predictand & $\hat{N}$ & $\hat{E}$ & $\hat{D}$ & $\hat{I}$ \\
\hline $\begin{array}{l}\text { Number of predictors } \\
\text { Number of possible predictors } \\
\text { Total variance } \\
\text { Residual variance } \\
\text { Per cent reduction } \\
\text { Root-mean-square error }\end{array}$ & $\begin{array}{l}9 \\
194 \\
\left.13.1 \text { ( }^{\circ} \mathrm{Lat}\right)^{2} \\
\left.5.3 \text { ( }^{\circ} \mathrm{Lat}\right)^{2} \\
59 \\
2.30^{\circ} \mathrm{Lat}\end{array}$ & $\begin{array}{l}5 \\
194 \\
\left.19.5 \text { ( }{ }^{\circ} \mathrm{Lat}\right)^{2} \\
\left.7.2 \text { ( }{ }^{\circ} \mathrm{Lat}\right)^{2} \\
63{ }^{\circ} \\
2.64{ }^{\circ} \mathrm{Lat}\end{array}$ & $\begin{array}{l}6 \\
194 \\
112 \mathrm{mb}^{2} \\
63 \mathrm{mb}^{2} \\
44 \\
7.94 \mathrm{mb}\end{array}$ & $\begin{array}{l}6 \\
194 \\
63 \mathrm{mb}^{2} \\
41 \mathrm{mb}^{2} \\
35 \\
6.40 \mathrm{mb}\end{array}$ \\
\hline \multicolumn{5}{|l|}{ Type B: } \\
\hline Predictand & $\hat{N}$ & $\hat{E}$ & $\hat{D}$ & $I$ \\
\hline $\begin{array}{l}\text { Number of predictors } \\
\text { Number of possible predictors } \\
\text { Total variance } \\
\text { Residual variance } \\
\text { Per cent reduction } \\
\text { Root-mean-square error }\end{array}$ & $\begin{array}{l}5 \\
412 \text { (o }^{\circ}{ }^{2}{ }^{2} \text { Lat } \\
\left.6.3 \text { ( }^{\circ} \mathrm{Lat}\right)^{2} \\
52 \\
2.51{ }^{\circ} \mathrm{Lat}\end{array}$ & $\begin{array}{l}5 \\
412 \\
\left.19.5 \text { ( }^{\circ} \mathrm{Lat}\right)^{2} \\
\left.6.4{ }^{\circ} \mathrm{Lat}\right)^{2} \\
67 \\
2.54{ }^{\circ} \mathrm{Lat}\end{array}$ & $\begin{array}{r}8 \\
412 \\
112 \mathrm{mb}^{2} \\
55 \mathrm{mb}^{2} \\
51 \\
7.42 \mathrm{mb}\end{array}$ & $\begin{array}{l}- \\
- \\
-\end{array}$ \\
\hline
\end{tabular}


TABLE 5. Summary of independent predictions, with dependent predictions shown for comparative purposes. Root-mean-square errors are tabulated for predictions of $\hat{N}$ (24-hr northward displacement), $\hat{E}$ (24-hr eastward displacement), $\hat{D}$ (24-hr change in central pressure), and $I$ (24-hr change in intensity). Results for both Type A and B are indicated. The "Vector" column is the root-mean-square vector error of the predicted position of the cyclone.

\begin{tabular}{lcccccc}
\hline \hline & & $\begin{array}{c}\hat{N} \\
\text { Cases }\end{array}$ & $\begin{array}{c}\hat{E} \\
\left({ }^{\circ} \mathrm{Lat}\right)\end{array}$ & $\begin{array}{c}\text { Vector } \\
\left({ }^{\circ} \mathrm{Lat}\right)\end{array}$ & $\begin{array}{c}\hat{D} \\
\left({ }^{\circ} \mathrm{Lat}\right)\end{array}$ & $\begin{array}{c}\hat{I} \\
(\mathrm{mb})\end{array}$ \\
\hline $\begin{array}{l}\text { Dependent (A) } \\
\text { Dependent (B) }\end{array}$ & 352 & 2.30 & 2.64 & 3.50 & 7.94 & 6.40 \\
Independent (A) & 106 & 2.51 & 2.54 & 3.57 & 7.42 & - \\
Independent (B) & 106 & 2.59 & 3.06 & 4.01 & 8.70 & 6.55 \\
& & & 3.12 & 4.05 & 8.61 & - \\
\hline
\end{tabular}

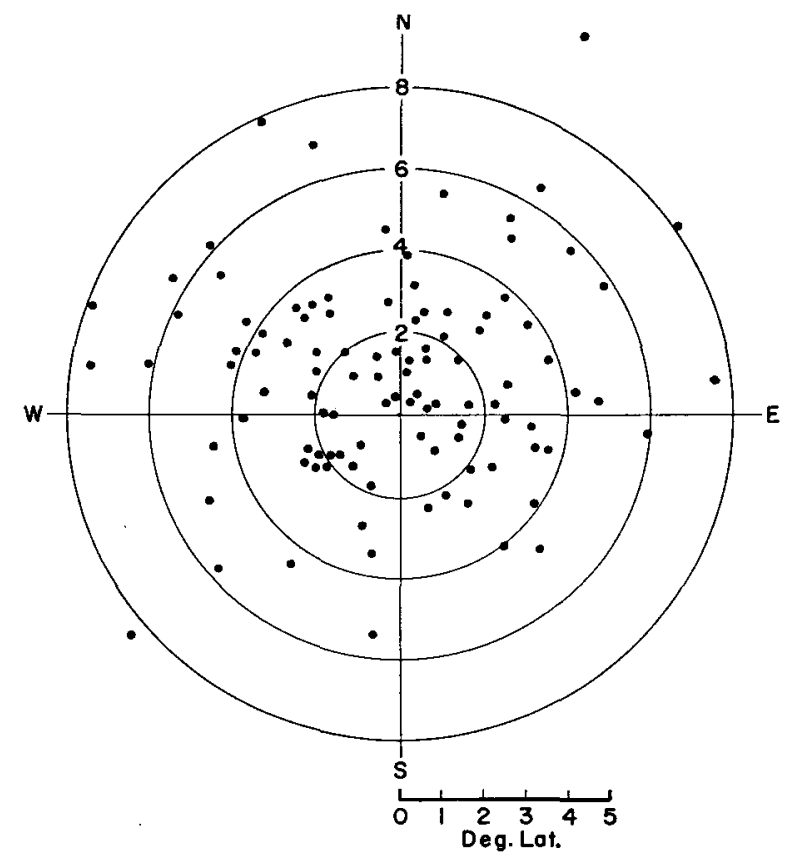

FIG. 5. Error distribution of 106 independent predictions of 24-hr cyclone displacement (Type A). Origin represents actual locations. The predicted locations are represented by circles plotted relative to the actual locations.

plotted relative to the observed location. Of these 106 predictions, 46 had a position error of less than $3 \mathrm{deg}$ of latitude. There were 20 cases in which the error was greater than 5 deg of latitude.

For the sample of 106 independent cases, a root-meansquare error of $8.70 \mathrm{mb}$ for central pressure was obtained. In several of the cases there were central pressure forecasts which, in terms of absolute differences between actual and forecast central pressure changes, exhibited fairly large errors but which in qualitative terms would, nevertheless, have been of distinct assistance to a forecaster. For example, compared with an actual change of $-40 \mathrm{mb}$, a predicted central pressure change of $-25 \mathrm{mb}$ results in an error of $15 \mathrm{mb}$. However, such a prediction is indicative of rapid deepening and would assist the forecaster who may be more concerned with the problem of whether a cyclone will fill, change little, deepen slightly, or deepen markedly, than he is with the precise magnitude of the change. An analysis of the central pressure predictions revealed that of the 22 cases in which the observed 24-hr deepening was $20 \mathrm{mb}$ or more, 5 cases were predicted to deepen at least $20 \mathrm{mb}, 14$ cases were predicted to deepen between 10 and $20 \mathrm{mb}, 3$ cases were predicted to deepen between 0 and $10 \mathrm{mb}$, and no cases were predicted to fill. Similarly, of the 14 cases predicted to deepen at least $20 \mathrm{mb}, 5$ cases were observed to deepen at least $20 \mathrm{mb}, 7$ cases were observed to deepen between 10 and $20 \mathrm{mb}, 2$ cases were observed to deepen between 0 and $10 \mathrm{mb}$, and no cases were observed to fill.

Thus, of the 22 cases in which the observed 24-hr deepening was $20 \mathrm{mb}$ or more, 19 were forecast to deepen at least $10 \mathrm{mb}$. Of the 14 cases in which deepening of of $20 \mathrm{mb}$ or more was predicled, 12 cases were observed to deepen at least $10 \mathrm{mb}$.

\section{Forecast examples}

Figs. 6 through 13 present examples of Type A predictions applied to independent data. Figs. 6 and 7 are two cases from the 106 independent data sample. The remainder are actual operational forecasts made during the winter of 1959-1960. The procedure for operational application has been described by Ostby and Veigas. ${ }^{12}$

Fig. 6. This is an early stage of the much-studied 1950 storm. The left side of the figure shows the initial sea-level pressure chart. The storm, located over the Carolinas, is predicted by the Type A regression equations to move north-northeastward to eastern Pennsylvania in 24 hours, with a central pressure of $994 \mathrm{mb}$. The map at verification time is shown in the right half of the figure. Although the forecast position is in error by 4.7 deg of latitude, the prediction did indicate that the storm would stay inland rather than move out over the Atlantic. The forecast central pressure of $994 \mathrm{mb}$ is $11 \mathrm{mb}$ too high.

Fig. 7. This is the same storm 12 hours later. The forecast northwestward movement is striking since most statistical forecasts exhibit a strong tendency to predict the climatological (i.e., northeastward) direction. The position error is only $2.0 \mathrm{deg}$ of latitude. The forecast central pressure is $5 \mathrm{mb}$ too high.

For the remaining examples, 18 -hr forecasts prepared by the National Weather Analysis Center (NWAC) are shown for comparison with the statistical predictions. Both predictions are valid for the same verifying

\footnotetext{
${ }^{12}$ Ostby, F. P., and K. W. Veigas, 1960: A moving-coordinate prediction model applied to east coast cyclones. Scientific Report No. 1, Contract No. AF19(604) -5207, Travelers Weather Research Center, 57-61.
} 


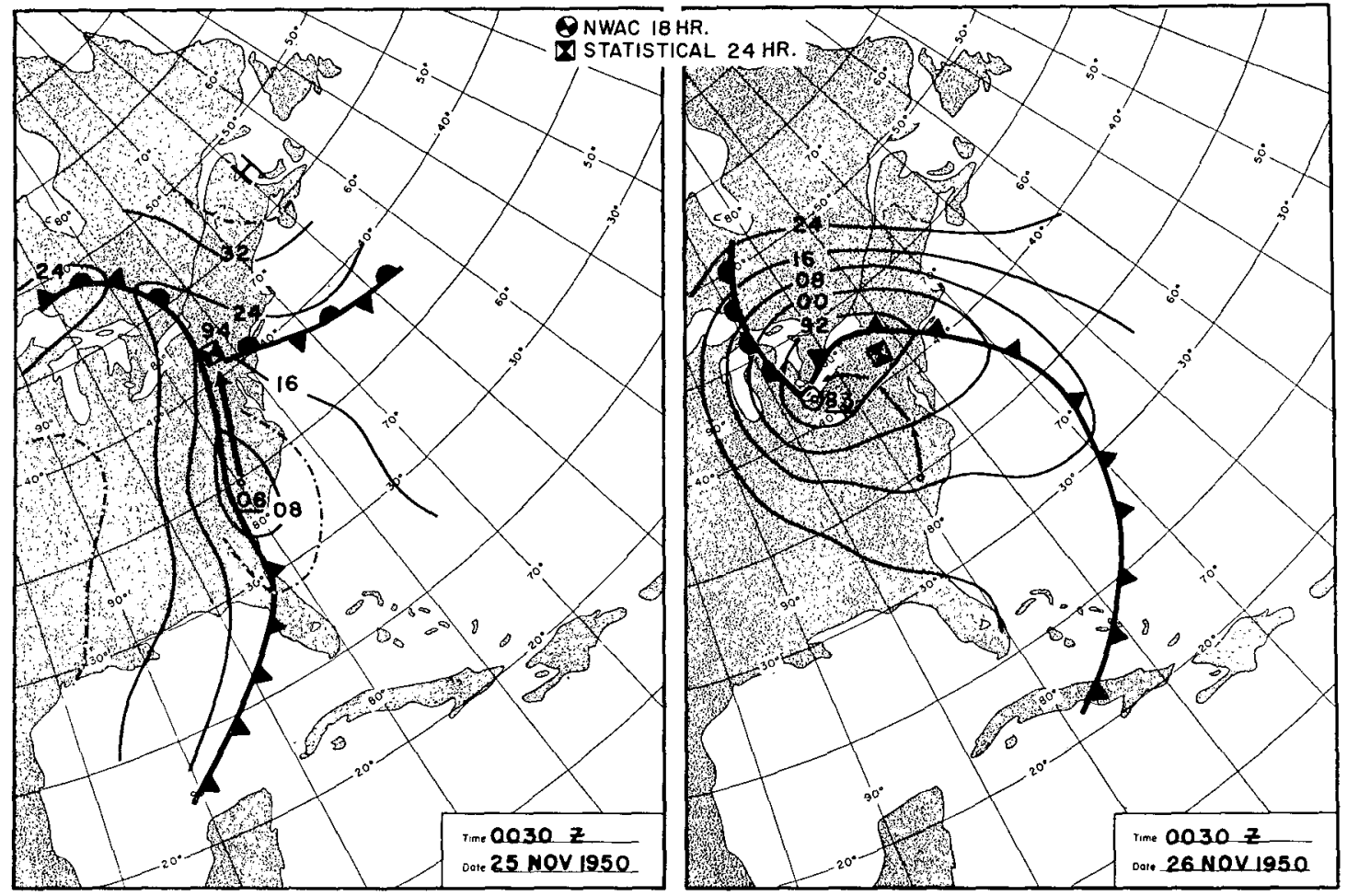

FIG. 6. Forecast example showing initial and verifying sea-level pressure charts. Solid arrow connects the initial and predicted cyclone locations. Broken arrows show the actual cyclone track.

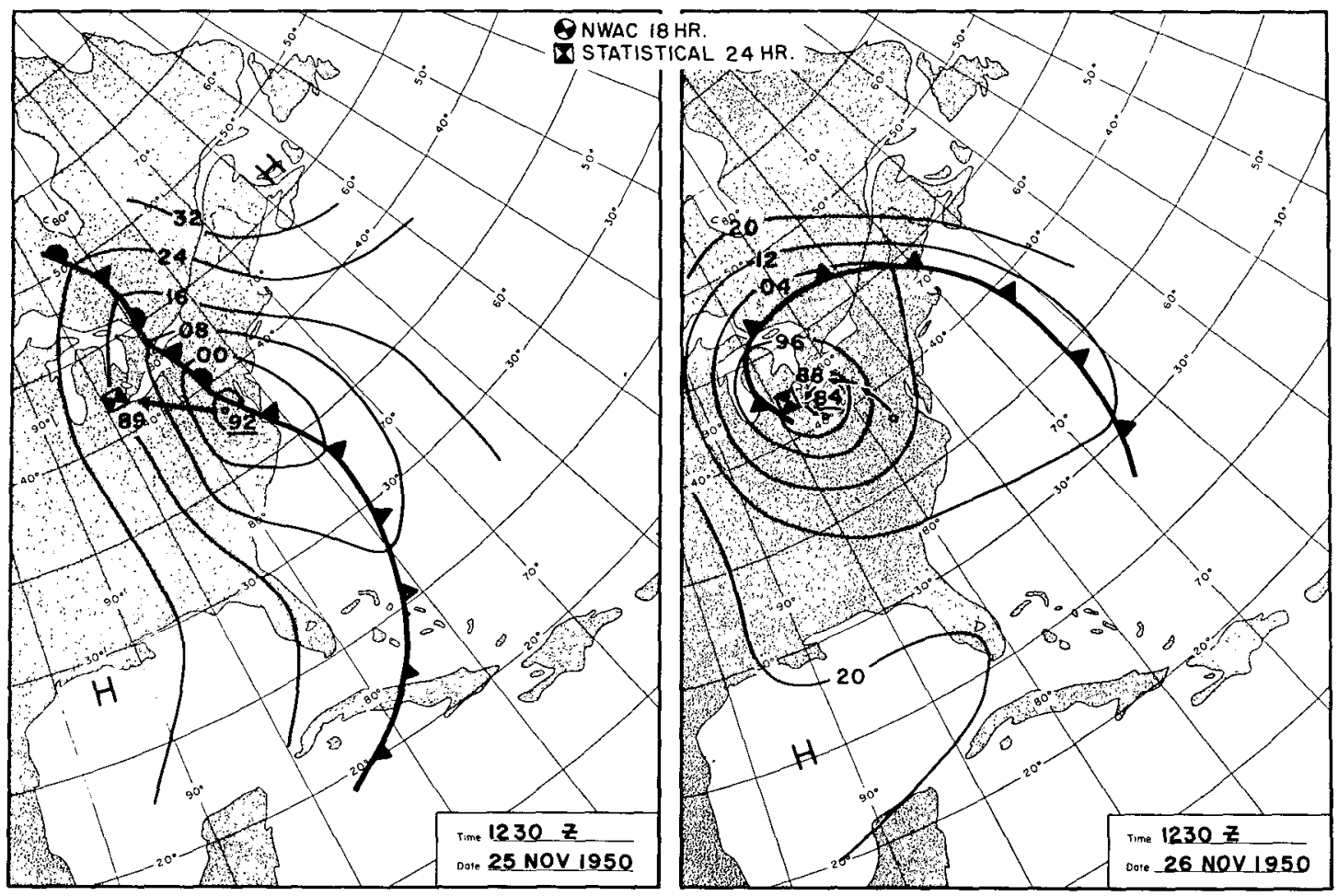

Frg. 7. Forecast example showing initial and verifying sea-level pressure charts. Solid arrow connects the initial and predicted cyclone locations. Broken arrows show the actual cyclone track. 


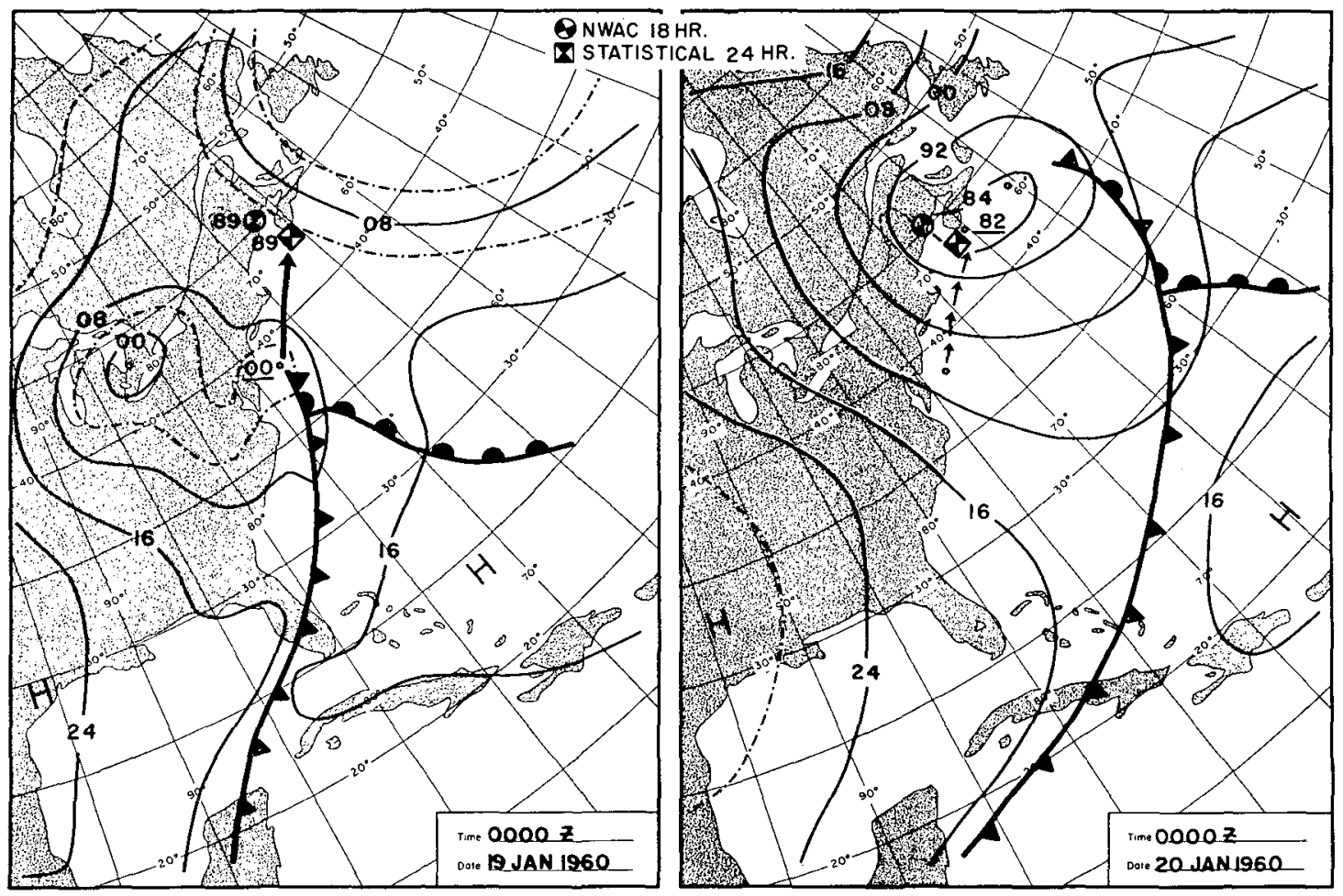

FIG. 8. Forecast example showing initial and verifying sea-level pressure charts. Solid arrow connects the initial and predicted cyclone locations. Broken arrows show the actual cyclone track.

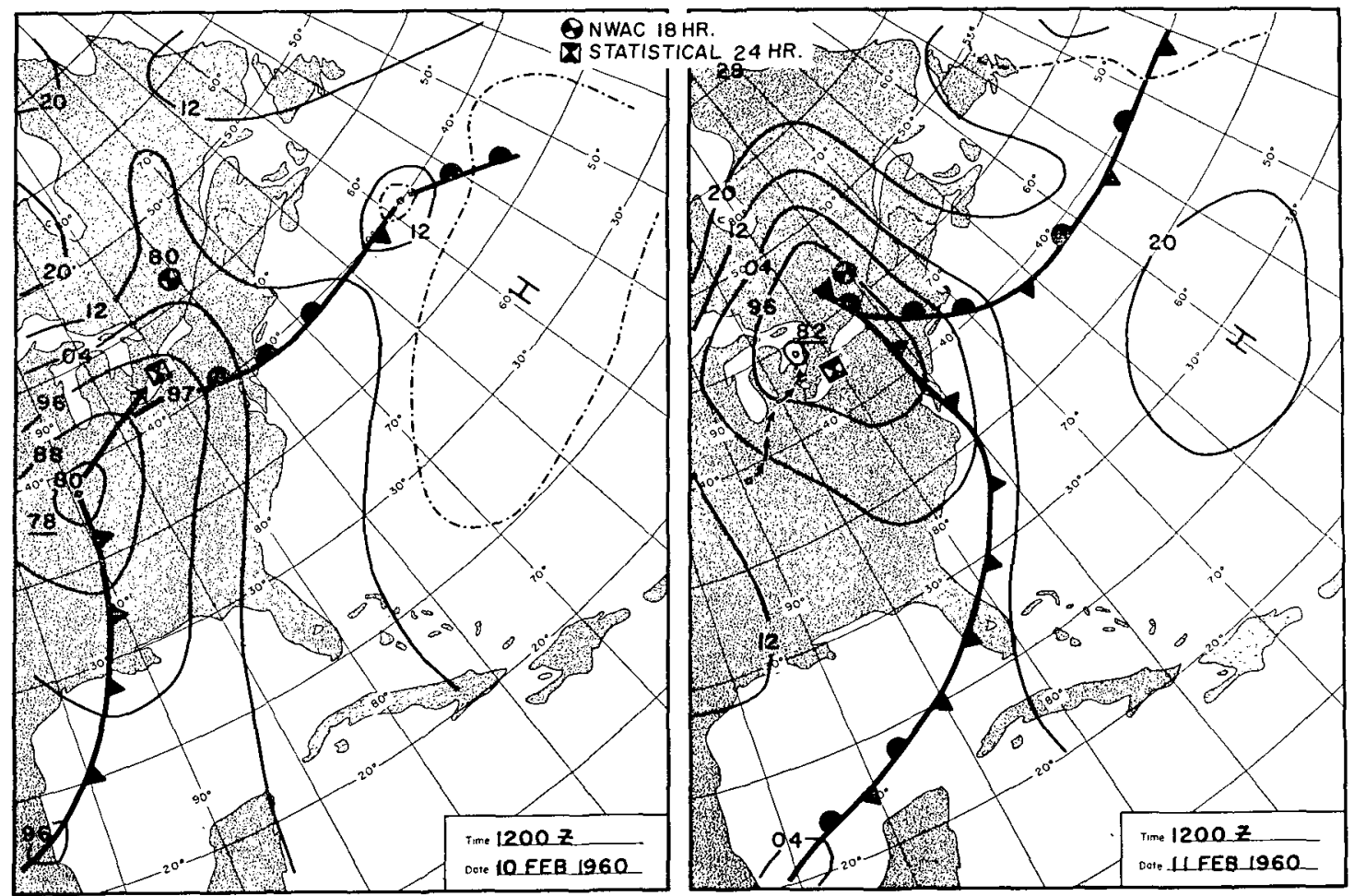

FIG. 9. Forecast example showing initial and verifying sea-level pressure charts. Solid arrow connects the initial and predicted cyclone locations. Broken arrows show the actual cyclone track. 


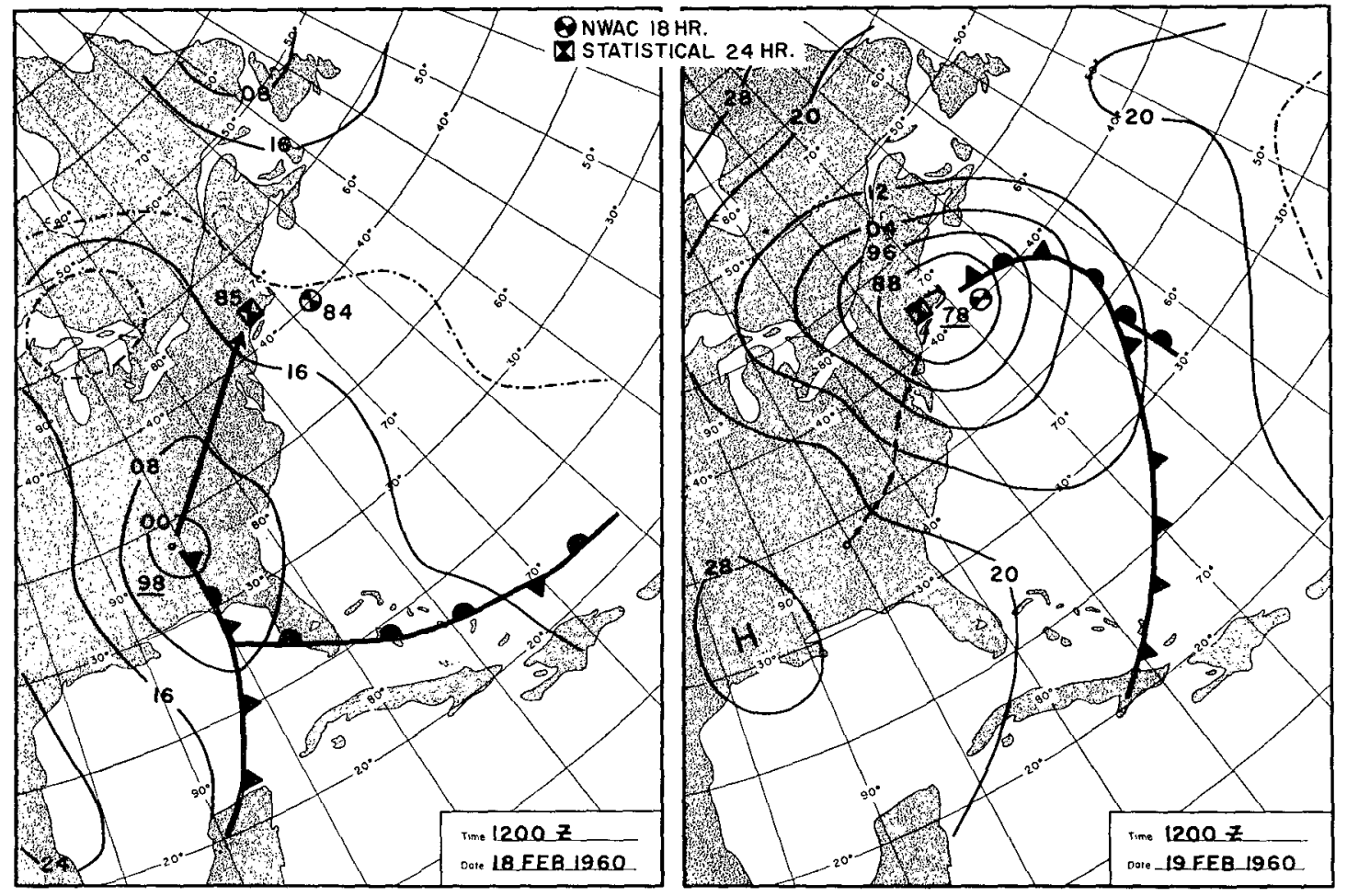

FIG. 10. Forecast example showing initial and verifying sea-level pressure charts. Solid arrow connects the initial and predicted cyclone locations. Broken arrows show the actual cyclone track.

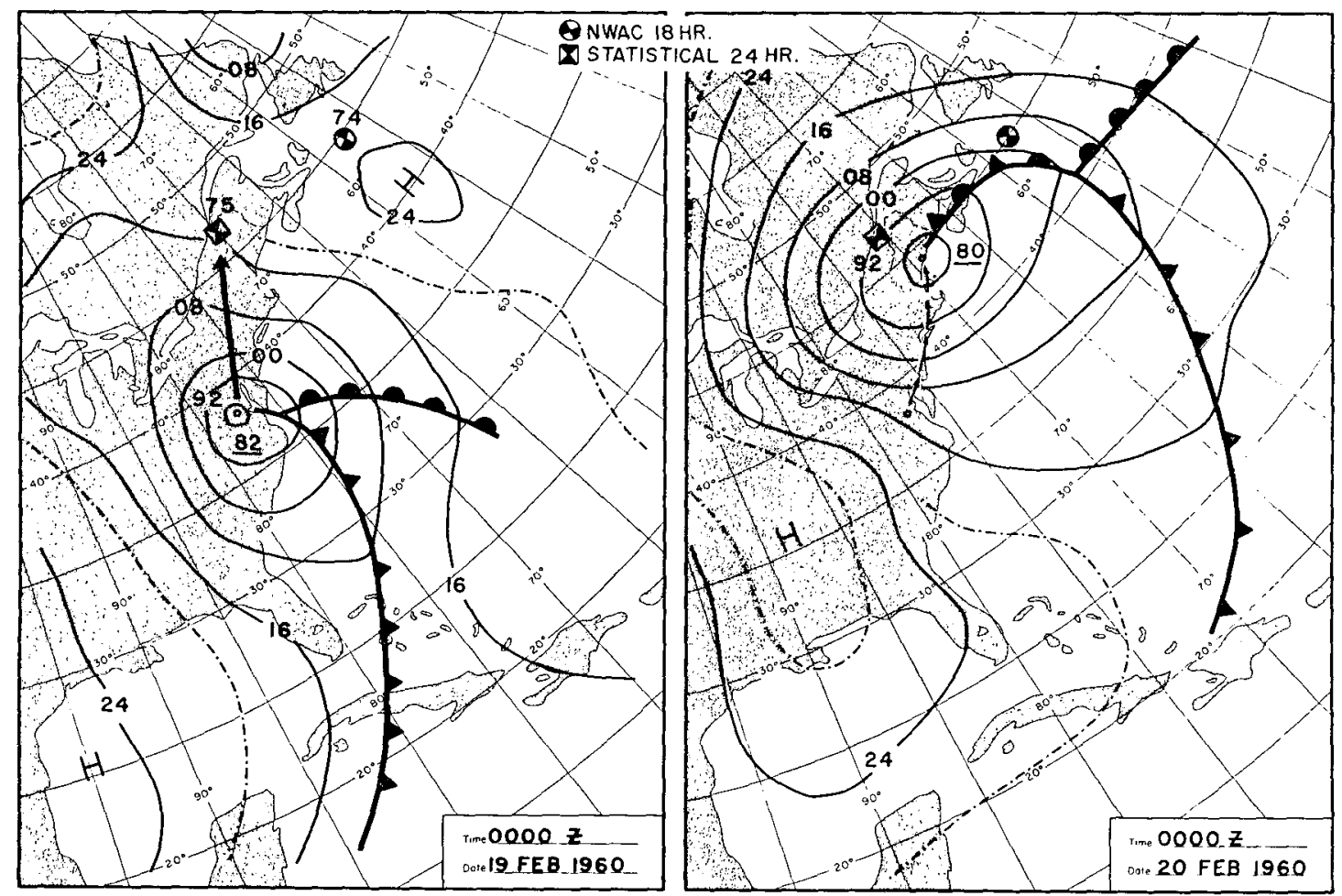

FIG. 11. Forecast example showing initial and verifying sea-level pressure charts. Solid arrow connects the initial and predicted cyclone locations. Broken arrows shown the actual cyclone track. 


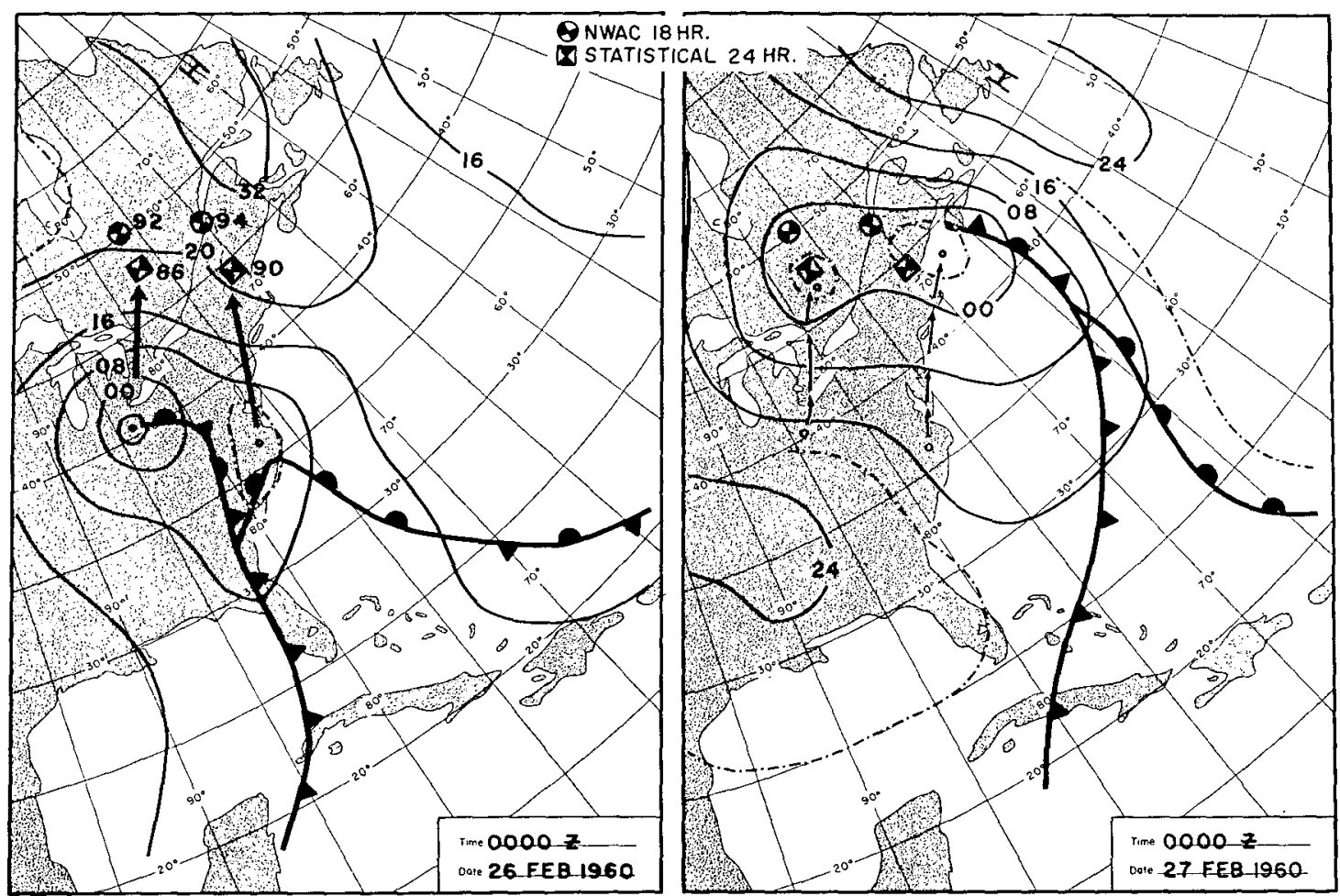

FIG. 12. Forecast example showing initial and verifying sea-level pressure charts. Solid arrow connects the initial and predicted cyclone locations. Broken arrows show the actual cyclone track.

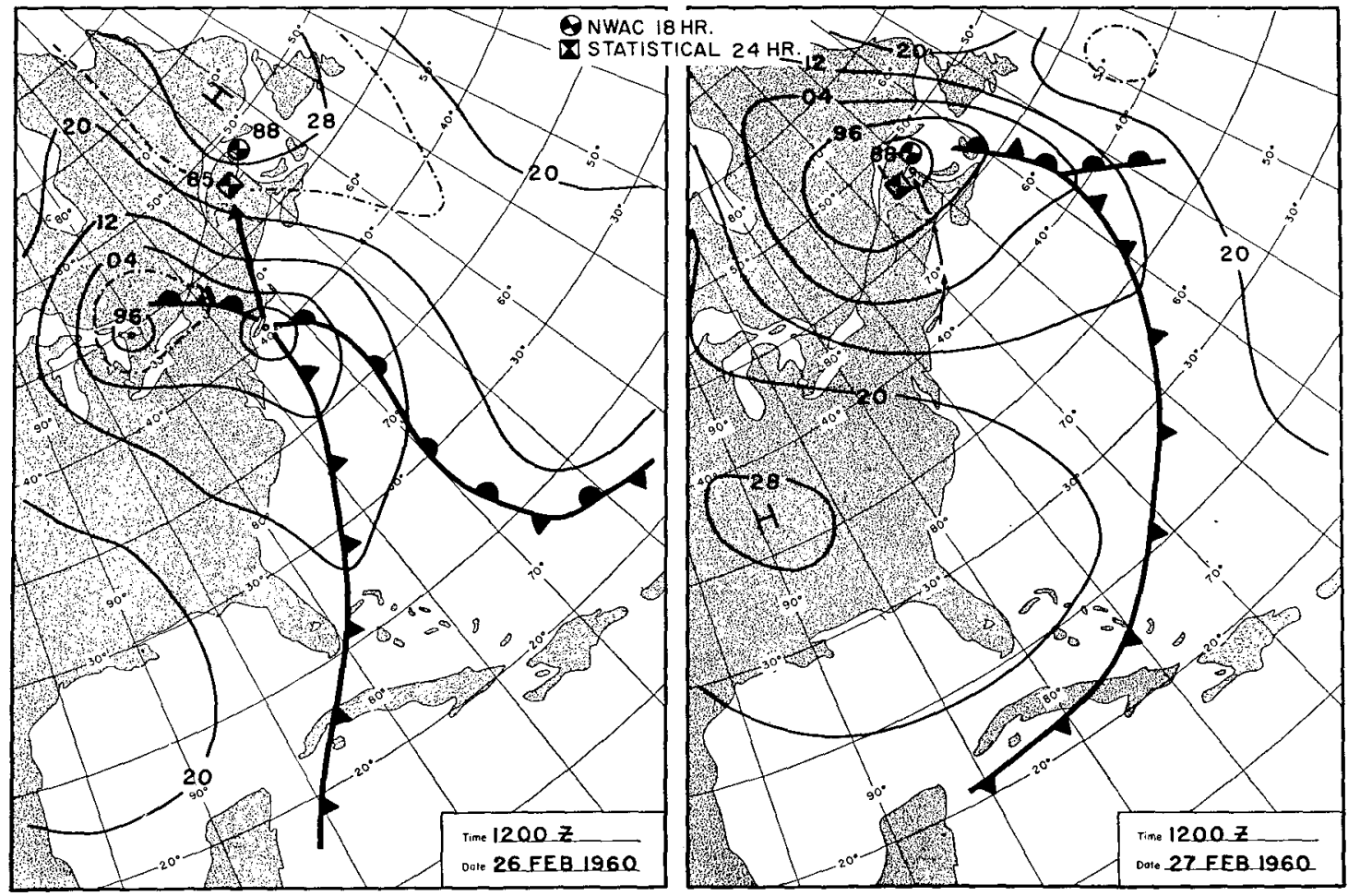

FIG. 13. Forecast example showing initial and verifying sea-level pressure charts. Solid arrow connects the initial and predicted cyclone locations. Broken arrows show the actual cyclone track. 
time. These operational forecasts were made using NWAC facsimile analyses exclusively for both initial and verifying conditions.

Fig. 8. The developing cyclone off the New Jersey coast on 19 January 1960 is predicted to move northeastward to the Gulf of Maine with a central pressure of $989 \mathrm{mb}$. The position error is 0.4 deg of latitude; the central pressure is $7 \mathrm{mb}$ too high. The NWAC $18-\mathrm{hr}$ prediction has a position error of $2.1 \mathrm{deg}$ of latitude and is also $7 \mathrm{mb}$ too high.

Fig. 9. This is a case in which the cyclone was located outside the forecast area at the initial time, $1200 \mathrm{GCT}$ 10 February 1960. This case involved a deep cyclone with an initial central pressure of $978 \mathrm{mb}$. The statistical prediction filled this storm $9 \mathrm{mb}$, which is exactly what occurred. The 18-hr NWAC prognosis was $7 \mathrm{mb}$ too high. The statistical and NWAC position errors were 2.1 and 4.9 deg latitude, respectively.

Fig. 10. This cyclone of 18 February 1960 was predicted to move northeastward and deepen to $985 \mathrm{mb}$. The forecast position was within $1.1 \mathrm{deg}$ of latitude of the observed position; the central pressure was $7 \mathrm{mb}$ too high. NWAC's position error was $2.7 \mathrm{deg}$ of latitude; the central pressure was $6 \mathrm{mb}$ too high.

Fig. 11. This case involves the same storm as in Fig. 10, 12 hours later. The statistical technique predicted a northeastward displacement with a central pressure of $975 \mathrm{mb}$. NWAC's 18-hr prognosis showed a rather large position error of $7.9 \mathrm{deg}$ of latitude; the central pressure was $6 \mathrm{mb}$ too low. The statistical prediction errors were $2.8 \mathrm{deg}$ of latitude and $-5 \mathrm{mb}$.

Fig. 12. This is an illustration of the application of the technique to two cyclones located in the forecast area at the same time, 0000 GCT 26 February 1960. The errors for the Ohio cyclone were $0.8 \mathrm{deg}$ of latitude and $-8 \mathrm{mb}$ for the statistical forecast, and $3.1 \mathrm{deg}$ of latitude and $-2 \mathrm{mb}$ for the NWAC forecast. For the North Carolina cyclone the errors were $2.6 \mathrm{deg}$ of latitude and $-3 \mathrm{mb}$ for the statistical forecast, and $4.2 \mathrm{deg}$ of latitude and $1 \mathrm{mb}$ for the NWAC forecast.

Fig. 13. This case involves the cyclone that was over North Carolina in Fig. 12, 12 hours later. The errors for statistical and NWAC forecasts are $0.8 \mathrm{deg}$ of latitude and $-1 \mathrm{mb}$, and $1.2 \mathrm{deg}$ of latitude and $1 \mathrm{mb}$, respectively.

In all, there were 31 cases in which it was possible to compare the statistical and NWAC forecasts. The rootmean-square error for cyclone location was $2.25 \mathrm{deg}$ of latitude for the 24-hr statistical forecasts and $3.87 \mathrm{deg}$ of latitude for the 18-hr NWAC forecasts. Root-meansquare errors of central pressure were $8.14 \mathrm{mb}$ for the statistical forecasts and $7.25 \mathrm{mb}$ for the NWAC forecasts. In 24 of the 31 forecasts of cyclone locations and in 13 of the 31 forecasts of central pressure, the statistical predictions yielded smaller errors than did the National Weather Analysis Center predictions.

\section{Summary}

The results of the research conducted during this study may be summarized as follows:

$a$. Complex type predictors failed to augment the predictive information contained in the simple point value prediction equations.

$b$. The prediction equations remained stable when applied to the sample of 106 independent cases.

c. An operational test during the winter months, 1959-1960, indicated that forecasts based on the derived equations were competitive with the National Weather Analysis Center forecasts.

$d$. The equations predicted, with reasonable accuracy, the unusual events of westerly or southerly cyclone movement in 5 of the 8 cases in the independent sample in which such movement occurred.

$e$. The prediction equations have general applicability to east coast cyclone forecasting: a past history of the cyclone track is not required, nor are the equations restricted to any particular synoptic pattern such as southwesterly flow aloft.

$f$. Use of the equations involves a simple, straightforward computational procedure, requiring only the use of a desk calculator.

Contrary to the results of earlier fixed coordinate experiments, inclusion of upper-air information in the statistical analysis resulted in an improvement in prediction over that achieved by sea-level pressures alone. On the other hand, in agreement with earlier studies, it was not possible to gain any significant improvement over point value predictions by including complex predictors. Both of these results, of course, will be critical factors, in the design of future experiments.

Finally, the stability of the equations, as well as their general and straightforward applicability, suggests the importance of further study both of the concept of a moving coordinate system in general and of its applicability to the problem of cyclone prediction in particular.

Acknowledgments. The authors wish to express their appreciation to Messrs. John E. Emerson and Joseph A. Sekorski for tabulating the data, to Mr. Charles W. Whitmore for aid in programming, and to Mr. Bernard Shorr for editorial assistance.

\section{REFERENCES}

Austin, J. M., 1947 : An empirical study of certain rules for forecasting the movements and intensity of cyclones. J. Meleor., 4, 16-20.

Bowie, E. H., and R. H. Weightman, 1914: Types of storms of the United States and their average movements. Mon. Wea. Rev., Supplement 1, 114 pp.

Charney, J. G., 1954: N'umerical prediction of cyclogenesis. Proc. Natl. Acad. Sci. U. S., 40, 99-110.

Estoque, M. A., 1957: Graphical integrations of a two-level model. J. Meteor., 14, 38-42.

Hering, W. S., and W. D. Mount, 1956: Evaluation of techniques for predicting the displacement of northeastward-moving cyclones. Bull. Amer. meteor. Soc., 37, 55-60. 
Longley, R. W., 1947: A study of the relationship between the $700-\mathrm{mb}$ flow and the movement of surface pressure centers. J. Meleor., 4, 202-204.

Miller, J. E., 1946: Cyclogenesis in the Atlantic coastal region. J. Meteor., 3, 31-44.

Miller, R. G., 1962: Statistical prediction by discriminant analysis. Meteor. Monographs 4 (25) , 45-47.

- , and T. F. Malone, 1954: Application of synoptic climatology to an objective technique for preparing sea-level prognostic pressure maps. Abstract in Bull. Amer. meteor. Soc., 35, 495-496.

Palmer, W. C., 1948: On forecasting the direction of movement of winter cyclones. Mon. Wea. Rev., 76, 181-201.

Petterssen, S., 1956: Weather analysis and forecasting. New York, McGraw-Hill Book Company, 428 pp.
—, M. A. Estoque, and L. A. Hughes, 1957: An experiment in prognostication. J. Meteor., 14, 191-205.

Rampey, E. M., 1953: Forecasting the speed of movement of selected cyclones along upper-air steering channels. $J$. Meteor., 10, 191-196.

Snedecor, G. W., 1946: Statistical methods. Ames, Iowa, Collegiate Press, $485 \mathrm{pp}$.

Sutcliffe, R. C., 1947: A contribution to the problem of development. Quart. J. R. meteor. Soc., 73, 370-383.

- - and A. G. Forsdyke, 1950: The theory and use of upper air thickness patterns in forecasting. Quart. J. R. meteor. Soc., 76, 189-217.

Wadsworth, G. P., and J. G. Bryan, 1948: Short range and extended forecasting by statistical methods. Air Weather Service Tech. nical Report No. 105-37, 202 pp. 